\title{
BMJ Open Cost-effectiveness analysis of different screening strategies for colorectal cancer in Guangzhou, southern China: a Markov simulation analysis based on natural community screening results
}

Qin Zhou (D) , ${ }^{1}$ Hai-lin Li, ${ }^{1}$ Yan Li, ${ }^{1}$ Yu-ting Gu, ${ }^{2}$ Ying-ru Liang, ${ }^{1}$ Hua-zhang Liu, ${ }^{1}$ Ke Li, ${ }^{1}$ Hang Dong, ${ }^{1}$ Yuan-yuan Chen, ${ }^{1}$ Guo-zhen Lin ${ }^{1}$

To cite: Zhou Q, Li H, Li Y, et al. Cost-effectiveness analysis of different screening strategies for colorectal cancer in Guangzhou, southern China: a Markov simulation analysis based on natural community screening results. BMJ Open 2021;11:e049581. doi:10.1136/ bmjopen-2021-049581

- Prepublication history for this paper is available online. To view these files, please visit the journal online (http://dx.doi. org/10.1136/bmjopen-2021049581).

Received 28 January 2021 Accepted 16 August 2021

Check for updates

(c) Author(s) (or their employer(s)) 2021. Re-use permitted under CC BY-NC. No commercial re-use. See rights and permissions. Published by BMJ.

${ }^{1}$ Non-Communicable Chronic Disease Control and Prevention, Guangzhou Center for Disease Control and Prevention, Guangzhou, Guangdong, China ${ }^{2}$ Medical Record Statistics,

Sun Yat-sen University First Affiliated Hospital, Guangzhou, Guangdong, China

Correspondence to

Dr Qin Zhou;

273142563@qq.com

\section{ABSTRACT}

Objectives To evaluate the cost-effectiveness of four different primary screening strategies: high-risk factor questionnaire (HRFQ) alone, single immunochemical faecal occult blood test (iFOBT), double iFOBT and HRFQ+double iFOBT for colorectal cancer (CRC) screening compared with no screening using the Markov model.

Methods Treeage Pro V.2011 software was used to simulate the Markov model. The incremental costeffectiveness ratio, which was compared with the willingness-to-pay (WTP) threshold, was used to reflect the cost-effectiveness of the CRC screening method. One-way sensitivity analysis and probabilistic sensitivity analysis were used for parameter uncertainty.

Results All strategies had greater effectiveness because they had more quality-adjusted life years (QALYs) than no screening. When the WTP was $¥ 435762 /$ QALY, all screening strategies were cost-effective compared with no screening. The double iFOBT strategy was the best-buy option compared with all other strategies because it had the most QALYs and the least cost. One-way sensitivity analysis showed that the sensitivity of low-risk adenoma, compliance with colonoscopy and primary screening cost were the main influencing factors comparing single iFOBT, double iFOBT and HRFQ +double iFOBT with no screening. However, within the scope of this study, there was no fundamental impact on cost-effectiveness. Probabilistic sensitivity analysis showed that when the WTP was $¥ 435762 /$ QALY, the probabilities of the cost-effectiveness acceptability curve with $\mathrm{HRFQ}$ alone, single $\mathrm{IFOBT}$, double iFOBT and HRFQ+double iFOBT were 0.0\%, 5.3\%, 69.3\% and $25.4 \%$, respectively.

Conclusions All screening strategies for CRC were costeffective compared with no screening strategy. Double iFOBT was the best-buy option compared with all other strategies. The significant influencing factors were the sensitivity of low-risk polyps, compliance with colonoscopy and cost of primary screening.

\section{BACKGROUND}

Globally, colorectal cancer (CRC) ranked third for cancer incidence but second for cancer death in 2018, with an estimate of
Strengths and limitations of this study

- The Markov model was used to evaluate the costeffectiveness of four different primary screening strategies for colorectal cancer (CRC) compared with no screening strategy, which was particular in China.

- Incremental cost-effectiveness ratios, which were compared with the willingness-to-pay threshold, were used to reflect the cost-effectiveness of the CRC screening method.

- Some parameters such as sensitivity and transition probability were from abroad or other early studies that may not be relevant to the Chinese population, particularly in Guangzhou.

- In the further study, it would be necessary to analyse the age-specific estimations of cost-effectiveness and obtain the accurate parameters.

1800977 new cases and 861663 deaths. ${ }^{1}$ In urban China, CRC ranked third in terms of incidence and fourth in terms of mortality. ${ }^{2}$ Both the crude incidence and the agestandardised rate have increased in recent years in the urban areas of China. ${ }^{34}$ The incidence and mortality were $41.77 / 10^{5}$ and $18.76 / 10^{5}$ in Guangzhou in 2015, ranking second and third of all the sites, respectively. ${ }^{5}$ The disease burden of CRC is severe in Guangzhou. ${ }^{6}$

CRC screening (CRCS) could significantly decrease the incidence and long-term mortality of CRC and increase the early detection rate. ${ }^{7-9}$ Many countries have carried out national CRCS programmes, such as the UK, the USA and Japan. ${ }^{10-13}$ Faecal occult blood tests (FOBTs) and colonoscopy are the most common screening methods worldwide. ${ }^{10-13}$ Cost-effectiveness analysis showed that all screening strategies were more cost-effective 
than no screening, but there was uncertainty as to which strategy was optimal. ${ }^{14-17}$ Cost-effectiveness simulation of CRCS indicated that immunochemical FOBT (iFOBT) every year may be the most effective in the Hong Kong Chinese population compared with no screening, guaiac immunologic fecal occult blood testing (gFOBT) and biennial iFOBT. ${ }^{18}$ However, the results abroad and in Hong Kong may not be generalisable to the Chinese population.

In China, a combination of the high-risk factor questionnaire (HRFQ) and FOBT is the most common screening strategy. Cost-effectiveness analysis on the urban Chinese population has shown that a combined use of FOBT and HRFQ is preferable in CRCS programmes as an initial screening instrument comparing FOBTs. ${ }^{19}$ Guangzhou has carried out the first-round screening of CRC in the community between 2015 and 2017. In this study, we evaluated the cost-effectiveness of four different primary screening strategies (HRFQ alone, single iFOBT, double iFOBT and HRFQ with double iFOBT) for CRC using the Markov model.

\section{MATERIALS AND METHODS}

\section{Patient and public involvement}

This study was part of the CRCS programme in Guangzhou 2015-2017. Participants were from the general community and hospitals. Written informed consent was obtained from all participants in the study. All the data collected in this study were coded. All names and personal information did not appear in the data or any publications.

\section{Study design}

Data for this study came from the CRCS programme in Guangzhou 2015-2017, Guangzhou Cancer Registry and published literature. The CRCS was undertaken from 1 January 2015 to 31 December 2017. A total of 371046 residents aged 50-74 years who agreed to participate in the study were included as participants. Participants were asked to take an HRFQ and/or double iFOBT as primary screening. If either the results of the questionnaire or FOBT were positive, both would be considered as a positive result. A positive result was followed by a colonoscopy. Then the individuals with negative results or not involved in screening should continue to participate in the screening in the next year until they have positive results or have reached the age of 75 years. While the individuals were over 75 years old, they would stop screening.

We compared five initial screening protocols: (1) HRFQ alone; (2) single iFOBT; (3) double iFOBT; (4) double iFOBT and HRFQ; and (5) no screening. All screening protocols were conducted as a primary screening, followed by a colonoscopy if the result of the primary screening was positive.

\section{Markov model}

Five screening strategies for CRC were compared in terms of cost and effectiveness under Markov simulation. Treeage Pro V.2011 software was used to simulate the Markov model. A hypothetical cohort of 100000 asymptomatic persons entered the model from 50 years old until death or 100 years old. In the model, each person had an initial health state. The natural history of colorectal adenomas and cancer is reflected in figure 1 .

\section{History of disease}

The disease states were divided into eight sections in the model: 'health', 'low-risk polyps', 'high-risk polyps', 'stage I CRC', 'stage II CRC', 'stage III CRC', 'stage IV CRC' and 'death'. Health status was defined as an asymptomatic state. According to the screening guidelines in Guangzhou, low-risk polyps were defined as adenomas that were $<1 \mathrm{~cm}$, while high-risk polyps were defined as adenomas where at least one was $\geq 1 \mathrm{~cm}$ or an adenoma with villous structure $(\geq 25 \%)$. All states were simulated as Markov states with a 1-year cycle. A person could transition to a different state or remain at current state at the end of every 1-year period in the Markov process.

In the no screening model, it was hypothesised that the health state could change to low-risk polyps, and then to high-risk polyps. High-risk polyps could change to stage I CRC; health state could change directly to stage I, II, III or IV CRC; and only stage I, II, III or IV CRC in patients could lead to death due to CRC. All states could change to death for any other reason; all states could remain in the same state (figure 1).

The disease history of the model for CRCS was also shown in figure 1, assuming that people are divided into two groups: those who participated in the screening and those who did not. Those who did not participate in the screening group were the same as the history of disease. It was hypothesised that the positive population in primary screening was divided into two groups: those who participated in colonoscopy and those who did not participate in colonoscopy.

All the patients with low-risk polyps and high-risk polyps according to CRCS were treated and could return to the health state after treatment, assuming that the disease history of the positive population in primary screening without colonoscopy and negative population in primary screening was the same as that of the no screening population.

\section{Transitional parameters}

The CRC incidence in all age groups was from the Guangzhou Cancer Registry Center. All-cause mortality and CRC mortality were from the Guangzhou Death Cause Surveillance System. The CRCS data were obtained from the CRCS programme in Guangzhou. Previous studies have shown that colonoscopic polypectomy of adenomas can reduce CRC incidence by approximately $76 \%-95 \%{ }^{20}$ In this study, we assumed a conservative reduction of $75 \%$. According to the suggestion of the WHO, the 


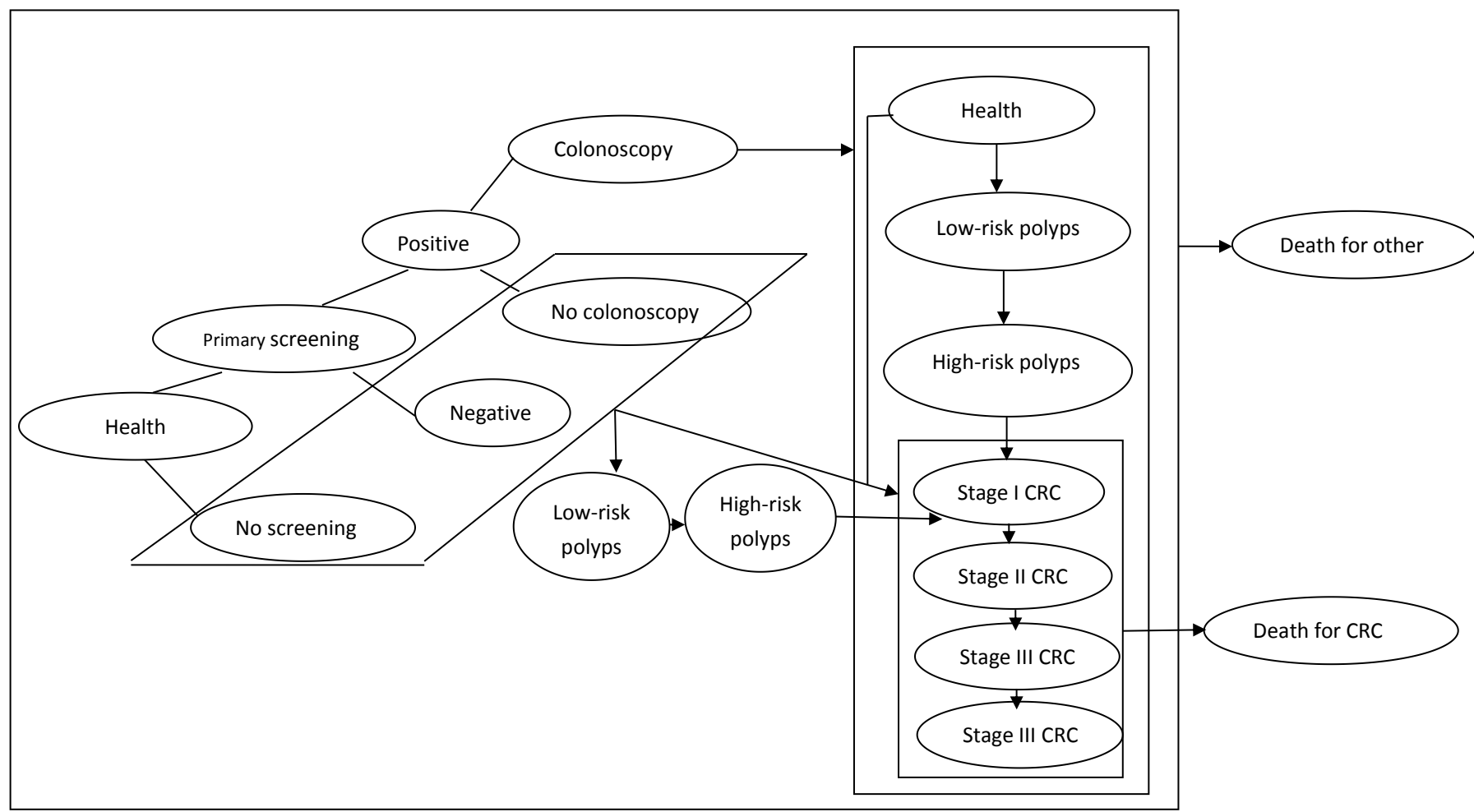

Figure 1 The CRC natural history of Markov simulation in screening and no screening status. CRC, colorectal cancer.

willingness-to-pay threshold was as three times as the gross domestic product, which was $¥ 145254$ in Guangzhou in 2016. Then, we assumed that the willingnessto-pay threshold was $¥ 435762$ / quality-adjusted life year (QALY). The data on health utility, transition probability and sensitivity were derived from the literature. All parameters are shown in tables 1 and 2 .

\section{Cost and effectiveness estimates}

All costs are shown as Chinese yuan in this study and were discounted until 2016. In this study, discount rates for both future costs and QALY were set at 3\%. The costs for CRCS included direct and indirect costs. It was assumed that the organisational management costs of screening did not differ among different screening groups. The primary screening costs comprised the materials, reagents, investigation process, management costs and labour expenditure. Effectiveness was shown with QALYs. By discounting the cost and effectiveness, the cumulative cost and per capita cumulative effectiveness of different screening methods can be obtained. The incremental cost-effectiveness ratio (ICER) can be obtained by comparing it with the willingness-to-pay threshold. A smaller ICER indicated a lower cost for saving one QALY. The most cost-effective strategy was identified by efficiency frontiers that the most incremental QALYs and the least cost were the most cost-effective.

\section{Sensitivity analysis}

In the study, the one-way sensitivity analysis of variables in the model was carried out. The cost data took the base value $( \pm 30 \%)$ as the maximum and minimum value. The utility data of the screening method took the $95 \%$ CI as the maximum and minimum value. The sensitivity and compliance data took $10 \%$ and $100 \%$ as the minimum and maximum values, respectively. The discount rate took $7 \%$ and $0 \%$ as the maximum and minimum values, respectively. A Tornado map was drawn.

Finally, the probabilistic sensitivity analysis was used for multivariate analysis. The model was simulated 1000 times. The cost data were subject to a gamma distribution. Utility data followed a log-normal distribution. The sensitivity and compliance data followed the beta distribution. The cost-effectiveness scatterplot and acceptability curve were used to test the stability of the model results.

\section{RESULTS}

After simulation over 50 years, the cumulative cost and utility per capita of the unscreened group were $¥ 29450$ and 19.39483 QALYs, respectively. All strategies were more effective than no screening because they provided more QALYs. The total costs of single iFOBT, HRFQ+double iFOBT and double iFOBT were less than no screening which showed cost-saving (see table 3). When the willingness-to-pay threshold was $¥ 435762 /$ QALY, all screening strategies were cost-effective compared with no screening (see table 4). The ICERs of the screening group with HRFQ alone, single iFOBT, HRFQ+double iFOBT and double iFOBT were ¥11480/QALY, - ¥23 110/QALY, - ¥27 564/QALY and - ¥38 516/QALY, respectively, compared with that of the no screening group. The 


\begin{tabular}{|c|c|c|c|c|c|}
\hline Variable & Values (range) & Reference & Variable & Values (range) & Reference \\
\hline \multicolumn{2}{|l|}{ CRC incidence $\left(1 / 10^{5}\right)$} & \multirow{6}{*}{$\begin{array}{l}\text { Cancer } \\
\text { statistics } \\
\text { report in } \\
\text { Guangzhou } \\
(2017-2018)^{5}\end{array}$} & \multicolumn{2}{|l|}{ Transition probability } & \multirow{5}{*}{$\begin{array}{l}\text { Chinese } \\
\text { reference }^{33}\end{array}$} \\
\hline $45-$ & 24.02 & & $\begin{array}{l}\text { Low-risk polyps-high- } \\
\text { risk polyps }\end{array}$ & 0.020 & \\
\hline $55-$ & 71.28 & & Stage I-stage II & 0.300 & \\
\hline $60-$ & 105.62 & & Stage II-stage III & 0.450 & \\
\hline $65-$ & 146.38 & & Stage III-stage IV & 0.500 & \\
\hline $70-$ & 207.13 & & Fatality rate & & $\begin{array}{l}\text { Chinese } \\
\text { reference }^{34}\end{array}$ \\
\hline \multicolumn{2}{|c|}{ Mortality of all causes other than $\operatorname{CRC}\left(1 / 10^{5}\right)$} & \multirow{8}{*}{$\begin{array}{l}\text { Death cause } \\
\text { surveillance } \\
\text { in Guangzhou } \\
(2014-2015)^{35}\end{array}$} & Stage III & 0.1001494 & \\
\hline $40-$ & 120.65 & & Stage IV & 0.2903332 & \\
\hline $45-$ & 201.37 & & Health utility value & & \multirow{6}{*}{$\begin{array}{l}\text { Hong Kong } \\
\text { reference }^{36}\end{array}$} \\
\hline $50-$ & 323.81 & & Low-risk polyps & $0.871 \pm 0.12$ & \\
\hline $55-$ & 489.62 & & High-risk polyps & $0.832 \pm 0.12$ & \\
\hline $60-$ & 694.20 & & Stage I CRC & $0.831 \pm 0.14$ & \\
\hline $65-$ & 1091.64 & & Stage II CRC & $0.858 \pm 0.12$ & \\
\hline $70-$ & 1973.18 & & Stage III CRC & $0.817 \pm 0.13$ & \\
\hline Colonoscopy & 340 & \multirow{3}{*}{$\begin{array}{l}\text { Medical } \\
\text { Service Price } \\
\text { in Guangdong } \\
\text { Province }^{38}\end{array}$} & Stage II CRC & $135443 \pm 7923$ & \multirow{3}{*}{$\begin{array}{l}\text { Chinese } \\
\text { reference }^{37}\end{array}$} \\
\hline $\begin{array}{l}\text { Pathology } \\
\text { examination }\end{array}$ & 172 & & Stage III CRC & $170396 \pm 9405$ & \\
\hline $\begin{array}{l}\text { Colonoscopic } \\
\text { polypectomy }\end{array}$ & 500 & & Stage IV CRC & $255679 \pm 21973$ & \\
\hline \multicolumn{2}{|c|}{ Proportion of stage I IV for screening (\%) } & CRCS & \multicolumn{2}{|c|}{ Proportion of stage I IV for no screening (\%) } & CRCS \\
\hline Stage I CRC & 37.306 & & Stage I CRC & 17.19 & \\
\hline Stage II CRC & 24.870 & & Stage II CRC & 25.55 & \\
\hline Stage III CRC & 27.979 & & Stage III CRC & 29.99 & \\
\hline Stage IV CRC & 9.845 & & Stage IV CRC & 27.27 & \\
\hline
\end{tabular}

$\mathrm{CRC}$, colorectal cancer; CRCS, CRC screening.

double iFOBT strategy was the most cost-effective strategy compared with the other strategies (see table 3).

\section{Sensitivity analysis}

One-way sensitivity analysis showed that the most influential factors on the results were the sensitivity of low-risk polyps, primary screening cost and health utility value of low-risk polyps comparing the HRFQ alone screening strategy with no screening. The sensitivity of low-risk polyps, compliance with colonoscopy and primary screening cost compared single iFOBT, double iFOBT and HRFQ+double iFOBT screening strategy with no screening, respectively (see figure 2). However, within 
Table 2 Parameters for different screening strategies in the Markov model: (1) single iFOBT; (2) double iFOBT; (3) HRFQ alone; (4) double iFOBT and HRFQ

\begin{tabular}{|c|c|c|c|c|c|}
\hline & $\begin{array}{l}\text { HRFQ alone } \\
\text { (range) }\end{array}$ & $\begin{array}{l}\text { Single iFOBT } \\
\text { (range) }\end{array}$ & $\begin{array}{l}\text { Double iFOBT } \\
\text { (range) }\end{array}$ & $\begin{array}{l}\text { HRFQ +double } \\
\text { iFOBT (range) }\end{array}$ & Reference \\
\hline $\begin{array}{l}\text { Uptake in primary } \\
\text { screening }\end{array}$ & $0.17(0.1-1.0)$ & $0.15(0.1-1.0)$ & $0.14(0.1-1.0)$ & $0.14(0.1-1.0)$ & CRCS \\
\hline $\begin{array}{l}\text { Positive result ratio in } \\
\text { primary screening }\end{array}$ & 0.10 & 0.06 & 0.08 & 0.16 & CRCS \\
\hline Uptake of colonoscopy & $0.16(0.1-1.0)$ & $0.25(0.1-1.0)$ & $0.26(0.1-1.0)$ & $0.19(0.1-1.0)$ & CRCS \\
\hline $\begin{array}{l}\text { Sensitivity of high-risk } \\
\text { polyps }\end{array}$ & $0.14^{\mathrm{a}}(0.1-1.0)$ & $0.47^{\mathrm{b}}(0.1-1.0)$ & $0.47^{\mathrm{a}}(0.1-1.0)$ & $0.58^{\mathrm{a}}(0.1-1.0)$ & $\begin{array}{l}\text { a: China reference }{ }^{39} \text { b: } \\
\text { Hong Kong reference }^{40}\end{array}$ \\
\hline Sensitivity of CRC & $0.10^{\mathrm{a}}(0.1-1.0)$ & $0.56^{\mathrm{c}}(0.1-1.0)$ & $0.70^{\mathrm{a}}(0.1-1.0)$ & $0.70^{\mathrm{a}}(0.1-1.0)$ & $\begin{array}{l}\text { a: China reference }{ }^{39} \mathrm{c} \text { : } \\
\text { Chinese reference }^{41}\end{array}$ \\
\hline
\end{tabular}

Uptake in primary screening means number of primary screening participators divided by target population; uptake of colonoscopy means number of colonoscopy participants divided by positive result of primary screening.

$\mathrm{CRC}$, colorectal cancer; CRCS, CRC screening; HRFQ, high-risk factor questionnaire; iFOBT, immunochemical faecal occult blood test.

the scope of this study, there was no fundamental impact on cost-effectiveness. The ICERs were still lower than the willingness-to-pay threshold, and with cost-effectiveness, screening was better than no screening.

With increasing compliance of colonoscopy and sensitivity of low-risk polyps, the ICERs decreased in all screening strategies (see figure 3), while with increasing primary screening cost, the ICERs increased in all screening strategies.

Probabilistic sensitivity analysis showed the difference of cost and effectiveness distribution which was significant among the five strategies (see figure 4). Furthermore, when the willingness-to-pay threshold was $¥ 435762$ / QALY, the probabilities of the cost-effectiveness acceptability curve with HRFQ alone, single iFOBT, double
iFOBT and HRFQ+double iFOBT were $0.0 \%, 5.3 \%$, $69.3 \%$ and $25.4 \%$, respectively (see figure 5 ).

\section{DISCUSSION}

The Markov model simulation showed that any screening strategy was more cost-effective than no screening strategy in Guangzhou. Globally, most population screening programmes for CRC are carried out by FOBTs, flexible sigmoidoscopy or colonoscopy. ${ }^{21}$ The economic evaluation showed that CRCS was more costeffective than other strategies, including newer technologies such as CT colonography (CTC), faecal DNA test and PillCam COLON compared with no screening. However, no strategy, whether alone or combined, has

Table 3 Cost and QALYs per person for each screening strategy, and the incremental cost and QALYs of a screening strategy

\begin{tabular}{|c|c|c|c|c|c|}
\hline Strategy & No screening & HRFQ alone & Single iFOBT & HRFQ +double iFOBT & Double iFOBT \\
\hline Cost per person & 29450.02675 & 29454.04466 & 29431.30783 & 29418.87898 & 29404.19321 \\
\hline $\begin{array}{l}\text { Incremental cost compared } \\
\text { with next best alternative }\end{array}$ & & 4.01791 & -22.73683 & -12.42885 & -14.68577 \\
\hline Expected QALYs per person & 19.39483 & 19.39518 & 19.39564 & 19.39596 & 19.39602 \\
\hline $\begin{array}{l}\text { Incremental QALYs compared } \\
\text { with next best alternative }\end{array}$ & & 0.00035 & 0.00046 & 0.00032 & 0.00006 \\
\hline Interpretation & & Dominated* & Cost-saving† & Dominated $\ddagger$ & $\begin{array}{l}\text { Cost-saving§ } \\
\text { (best-buy option) }\end{array}$ \\
\hline
\end{tabular}

*Dominated by single iFOBT, HRFQ+double iFOBT and double iFOBT as they provide more QALYs and less cost.

†Cost-saving when compared with no screening and HRFQ alone.

‡Dominated by double iFOBT as it provided more QALYs and required less cost.

§Cost-saving when compared with no screening, HRFQ alone, single iFOBT and HRFQ +double iFOBT.

HRFQ, high-risk factor questionnaire; ICERs, incremental cost-effectiveness ratios; iFOBT, immunochemical faecal occult blood test;

QALYs, quality-adjusted life years. 
Table 4 Cost and QALYs per person for each screening strategy, and the incremental cost and QALYs of a screening strategy compared with no screening

\begin{tabular}{|c|c|c|c|c|c|}
\hline Strategy & No screening & HRFQ alone & Single iFOBT & HRFQ +double iFOBT & Double iFOBT \\
\hline Cost per person & 29450.02675 & 29454.04466 & 29431.30783 & 29418.87898 & 29404.19321 \\
\hline $\begin{array}{l}\text { Incremental cost compared } \\
\text { with no screening }\end{array}$ & & 4.01791 & -18.71892 & -31.14777 & -45.83354 \\
\hline Expected QALYs per person & 19.39483 & 19.39518 & 19.39564 & 19.39596 & 19.39602 \\
\hline $\begin{array}{l}\text { Incremental QALYs compared } \\
\text { with no screening }\end{array}$ & & 0.00035 & 0.00081 & 0.00113 & 0.00119 \\
\hline $\begin{array}{l}\text { Interpretation (when } \\
\text { compared with no screening) }\end{array}$ & & Cost-effective & Cost-saving & Cost-saving & Cost-saving \\
\hline
\end{tabular}

HRFQ, high-risk factor questionnaire; ICERs, incremental cost-effectiveness ratios; iFOBT, immunochemical faecal occult blood test; QALYs, quality-adjusted life years.

been indicated definitively to be the most cost-effective method or has had a better ICER than the rest. ${ }^{14-17}$ Sarfati et al showed that faecal immunochemical test (FIT)-based screening was more cost-effective than oneoff sigmoidoscopy screening. The combination of oneoff sigmoidoscopy with the FIT was more cost-effective in saving lives than either modality alone. ${ }^{15}$ Some studies favoured FITs over gFOBTs concerning effectiveness and cost-effectiveness. $^{22-24}$ Hybrid faecal testing/colonoscopy appeared superior to plasma methylated Septin 9 DNA (mSEPT9) based screening in Germany. ${ }^{25}$ There was agreement among studies that the newly developed screening tests of stool DNA testing, CTC and capsule endoscopy were not yet cost-effective compared with the established screening options such as FIT screening. ${ }^{26} 27$ Phisalprapa et al indicated that the colonoscopy screening every 10 years was cost-effective compared with annual FIT in Thailand. ${ }^{28}$ However, in terms of human resources and budgetary burden, screening by annual FIT was more feasible. This also applies to China because of its large population and shortage of medical resources.

In this study, the double iFOBT was the most cost-effective strategy compared with single iFOBT, HRFQ +double iFOBT and HRFQ alone. This result was not consistent with Huang et al's finding that combined use of FOBT and HRFQ as an initial step for CRCS was a better strategy than FOBT alone. ${ }^{19}$ The compliance with colonoscopy both in the single iFOBT strategy and double iFOBT strategy was higher than that in the HRFQ +double iFOBT strategy. Analysis showed that the initial screening cost and compliance with colonoscopy significantly influenced the cost-effectiveness of CRCS. The higher the compliance of colonoscopy was, the better the cost-effectiveness of screening. The lower the screening cost was, the better the cost-effectiveness of screening. Skally et al showed that cost and compliance were the main influences on cost-effectiveness for fDNA as a CRCS tool. ${ }^{29}$ Huang et al showed that ICER was more sensitive to changes in initial screening coverage when colonoscopy compliance was higher. ${ }^{19}$ When compliance to such new techniques such as CTC was increased more than the established strategies, they would be more costeffective. ${ }^{14}$ Participation was an important factor for effectiveness and cost estimates. $^{27}$

To increase the cost-effectiveness of CRCS, it is necessary to increase the sensitivity of low-risk polyps, comply with colonoscopy and decrease the cost of screening. A related study showed that the expenditure of colonoscopy, which was paid by the examiner, significantly influenced the compliance of colonoscopy. ${ }^{30}$ The targeted reminder might be more cost-effective than the universal reminders when considering their effects on health disparity. ${ }^{31}$ Lara et al's study suggested that qualified health centres could provide appropriate technical support, such as patient and provider reminder systems, provider assessment and feedback, and numerous support activities, which were proven to be cost-effective. ${ }^{32}$ Improved sensitivity might be an effective method for increasing cost-effectiveness.

There are some limitations to this study. Some parameters such as sensitivity and transition probability were from abroad or other early studies that may not be relevant to the Chinese population, particularly in Guangzhou. In a further study, it would be necessary to analyse the agespecific estimations of cost-effectiveness and obtain accurate parameters.

\section{CONCLUSION}

In conclusion, all screening strategies for CRC were costeffective compared with no screening strategy. Double iFOBT was the best-buy option. The significant influencing factors were sensitivity of low-risk polyps, compliance with colonoscopy and the cost of primary screening. It was necessary to promote the screening of CRC, particularly colonoscopy, and decrease the cost of primary screening.

Acknowledgements We wish to acknowledge the staff of the Guangzhou and 12 district colorectal cancer screening programme offices and all the participants from the general community and hospital. 
Tornado map comparing $\mathrm{HRFQ}$ alone with no screening

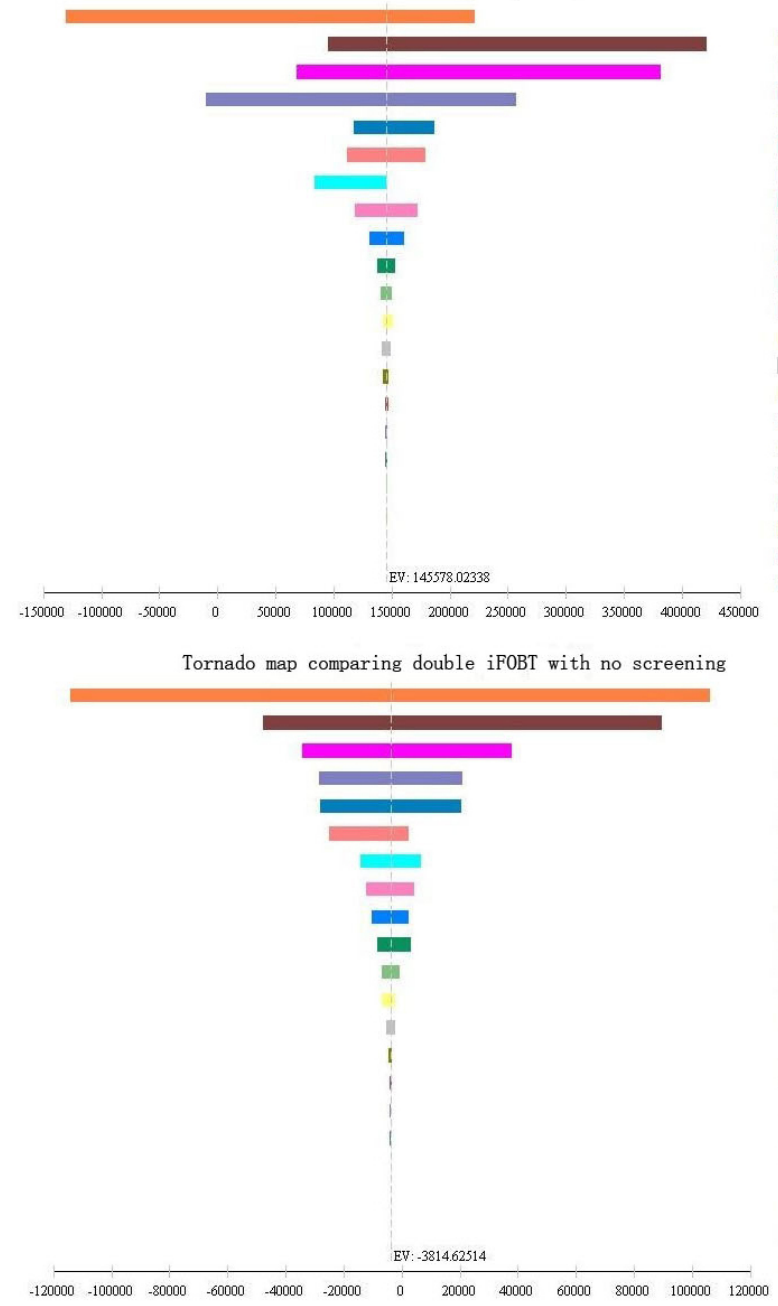

Tornado map comparing single iFOBT with no screening

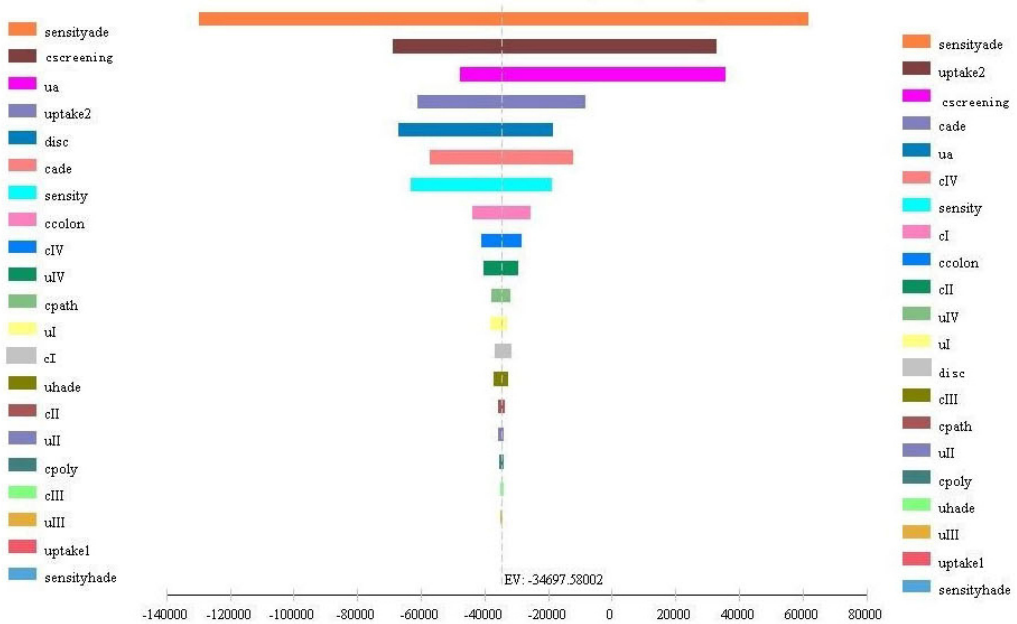

Tornado map comparing HRFQ+double iFOBT with no screening

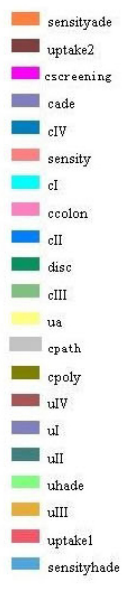

Figure 2 Tornado map comparing high-risk factor questionnaire (HRFQ) alone, single immunochemical faecal occult blood test (iFOBT), double iFOBT and HRFQ+double iFOBT colorectal cancer (CRC) screening strategies with no screening. cl, cost of stage I CRC; cll, cost of stage II CRC; clll, cost of stage III CRC; cIV, cost of stage IV CRC; cade, cost of adenoma; ccolon, cost of colonoscopy; cpath, cost of pathology; cpoly, cost of colonoscopic polypectomy; cscreening, primary screening cost; disc, discount rate; sensity, sensitivity; ; sensityade, sensitivity of low-risk polyps; sensityhade, sensitivity of high-risk polyps; ul, utility value of stage I CRC; ull, utility value of stage II CRC; ullI, utility value of stage III CRC; uIV, utility value of stage IV CRC; ua, utility value of low-risk polyps; uhade, utility value of high-risk polyps; uptake1, uptake of initial screening; uptake2, compliance with colonoscopy.

Contributors QZ, H-IL, YL, H-ZL and G-ZL conceived the study and participated in its design and coordination. QZ, Y-tG Y-rL, KL, HD and Y-yC performed the data collection. QZ and H-IL performed the statistical analyses and interpretation. QZ drafted the manuscript. All authors read and approved the final manuscript.

Funding This study was supported by the Natural Science Foundation of Guangdong Province (No. 2016A030313504), Guangzhou Science and Technology Program key projects (No. 201707010205), The Key Project of Medicine Discipline of Guangzhou (No.2021-2023-12) and Basic Research Project of Key Laboratory of Guangzhou (2021BRP004)

Competing interests None declared.

Patient and public involvement Patients and/or the public were involved in the design, or conduct, or reporting, or dissemination plans of this research. Refer to the Methods section for further details.

Patient consent for publication Not required.

Ethics approval Written informed consent to participate in the study was obtained from all participants. The ethics committee of the Guangzhou Center of Disease Control and Prevention approved this study proposal (GZCDC2016008).

Provenance and peer review Not commissioned; externally peer reviewed.
Data availability statement Data are available upon reasonable request. The datasets used or analysed during the current study are available from the corresponding author upon reasonable request.

Open access This is an open access article distributed in accordance with the Creative Commons Attribution Non Commercial (CC BY-NC 4.0) license, which permits others to distribute, remix, adapt, build upon this work non-commercially, and license their derivative works on different terms, provided the original work is properly cited, appropriate credit is given, any changes made indicated, and the use is non-commercial. See: http://creativecommons.org/licenses/by-nc/4.0/.

ORCID iD

Qin Zhou http://orcid.org/0000-0003-3637-8518

\section{REFERENCES}

1 Bray F, Ferlay J, Soerjomataram I, et al. Global cancer statistics 2018: GLOBOCAN estimates of incidence and mortality worldwide for 36 cancers in 185 countries. CA Cancer J Clin 2018;68:394-424. 


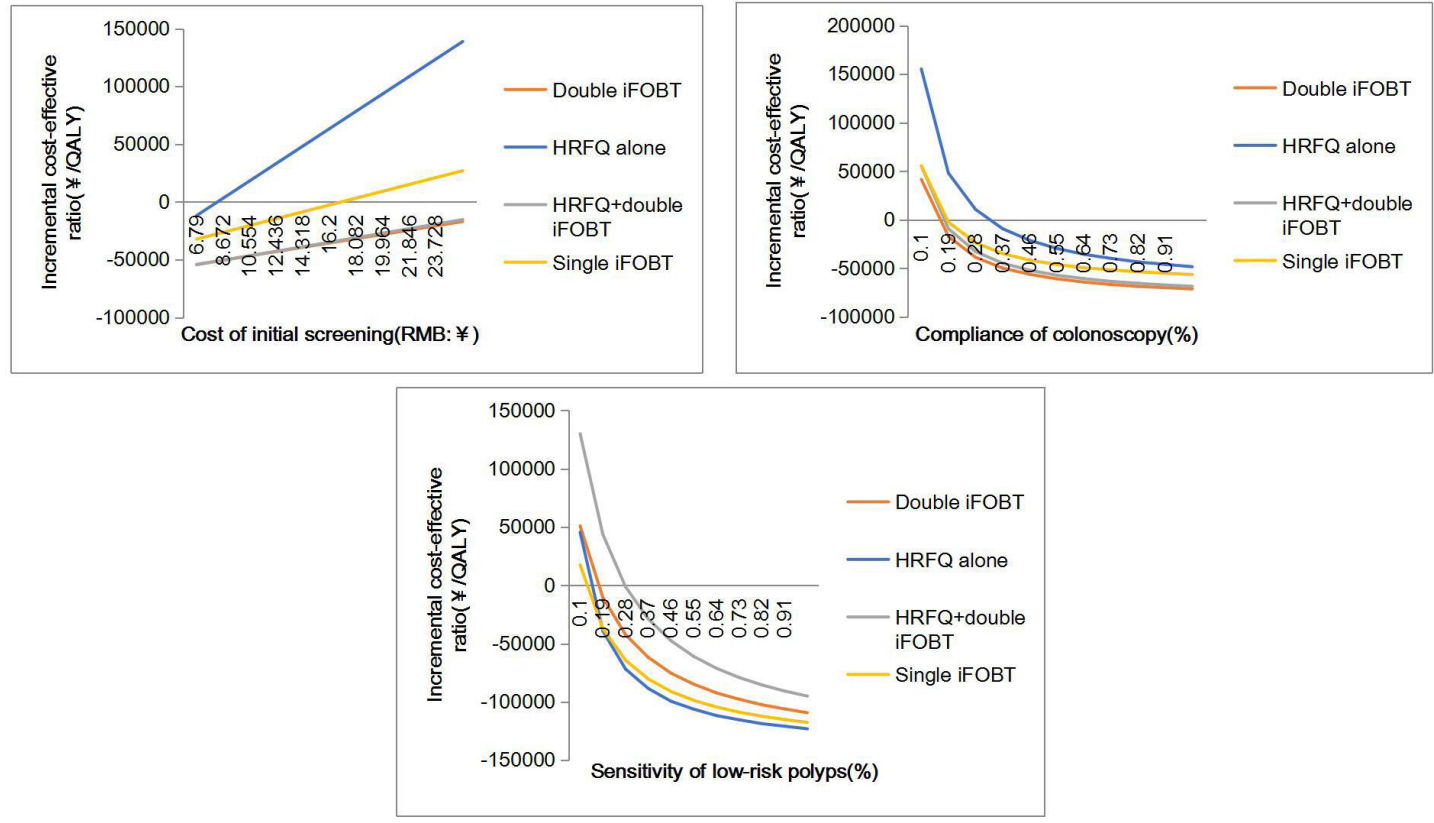

Figure 3 ICER changes with rising cost of initial screening, compliance with colonoscopy and sensitivity of low-risk polyps: one-way sensitivity analysis. HRFQ, high-risk factor questionnaire; ICER, incremental cost-effectiveness ratio: iFOBT, immunochemical faecal occult blood test; QALY, quality-adjusted life year.

2 He J, Chen WQ. Chinese cancer registry annual report, 2016. 1st ed. Beijing: Tsinghua university press, 2017: 76-8.

3 Dai Z, Zheng RS, Zou XN. Analysis and prdiction of colorectal cancer incidence trend in China. Chin J Prev Med 2012;46:598-603.

4 Zhang Y, Shi JF, Huang HY. Burden of colorectal cancer in China. Chin J Epidemiol 2015;36:709-14.

5 Liu HZ, Lin GZ. Cancer statistics report in Guangzhou (2017-2018). 1st ed. Guangzhou: Yangcheng Evening News Press, 2018: 23-6.

6 Zhou Q. Burden of disease of colorectal cancer in Guangzhou, 20102013. China Cancer 2017:26:948-52.

7 Zavoral M, Suchanek S, Majek O, et al. Colorectal cancer screening: 20 years of development and recent progress. World $\mathrm{J}$ Gastroenterol 2014:20:3825-34.

8 Shaukat A, Mongin SJ, Geisser MS, et al. Long-Term mortality after screening for colorectal cancer. N Engl J Med 2013;369:1106-14.

9 CDC. Vital signs: colorectal cancer screening, incidence and mortality-United states, 2002-2010. Available: http://www.cdc.gov/

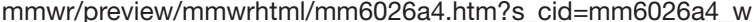

10 Kaminski MF, Kraszewska E, Rupinski M, et al. Design of the Polish colonoscopy screening program: a randomized health services study. Endoscopy 2015;47:1144-50.

11 Mayor S. England to start national bowel cancer screening programme. BMJ 2004;329:1061.2.

12 CDC. Vital signs: colorectal cancer screening, incidence and mortality-United states, 2002-2010. Available: http://www.cdc.gov/

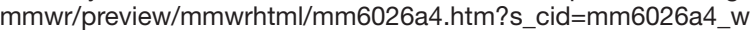
[Accessed 10 Dec 2015].

13 Saito $\mathrm{H}$. Colorectal cancer screening using immunochemical faecal occult blood testing in Japan. J Med Screen 2006;13 Suppl 1:S6-7.

14 Arafa MA, Farhat KH. Recent diagnostic procedures for colorectal cancer screening: are they cost-effective? Arab J Gastroenterol 2017;18:136-9.

15 Sarfati D, Shaw C, McLeod M, et al. Screening for colorectal cancer: spoiled for choice? N Z Med J 2016;129:120-8.

16 Patel SS, Kilgore ML. Cost effectiveness of colorectal cancer screening strategies. Cancer Control 2015;22:248-58.

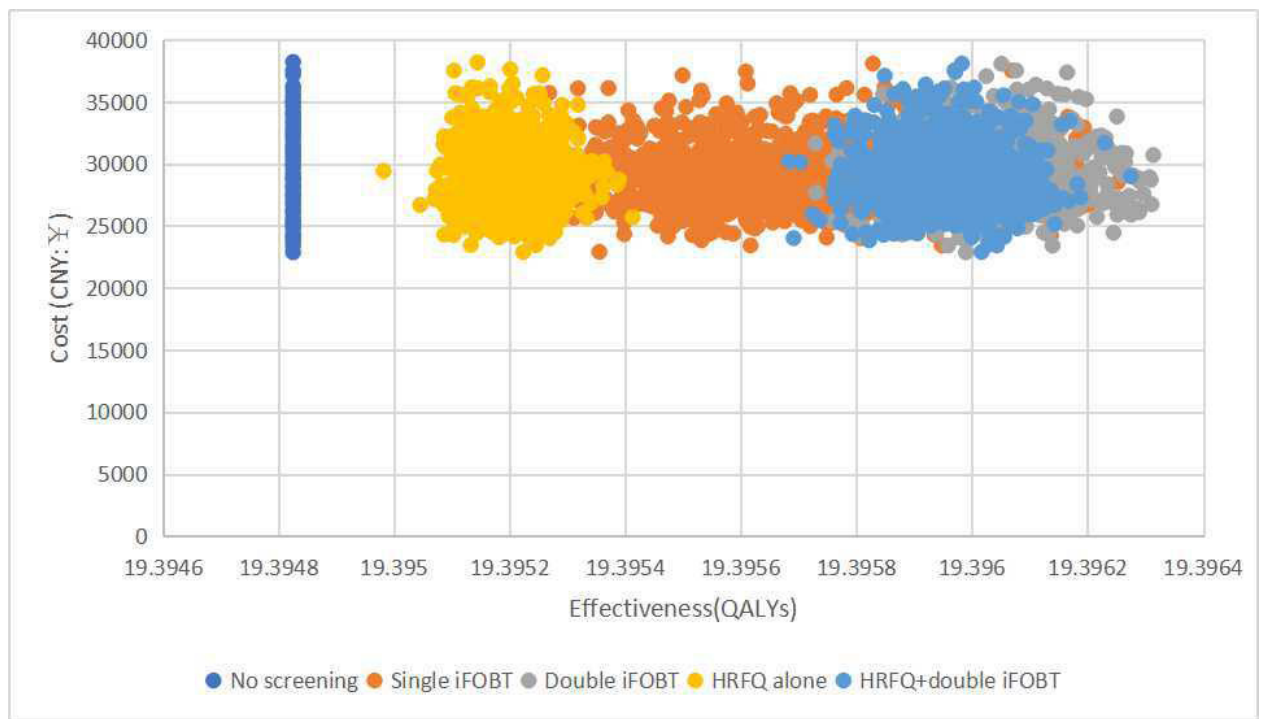

Figure 4 Cost-effectiveness scatterplot in terms of QALYs for all strategies. HRFQ, high-risk factor questionnaire; iFOBT, immunochemical faecal occult blood test; QALYs, quality-adjusted life years. 


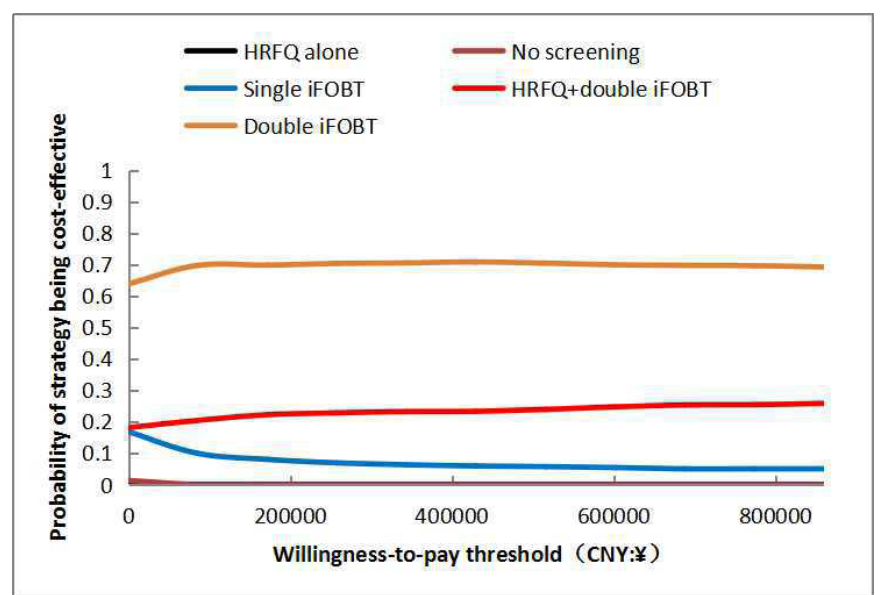

Figure 5 Cost-effectiveness acceptability curve in terms of QALYs for all strategies in probabilistic sensitivity analysis. HRFQ, high-risk factor questionnaire; iFOBT, immunochemical faecal occult blood test; QALYs, qualityadjusted life years.

17 Cruzado J, Sánchez FI, Abellán JM, et al. Economic evaluation of colorectal cancer (CRC) screening. Best Pract Res Clin Gastroenterol 2013;27:867-80.

18 Wong CKH, Lam CLK, Wan YF, et al. Cost-Effectiveness simulation and analysis of colorectal cancer screening in Hong Kong Chinese population: comparison amongst colonoscopy, guaiac and immunologic fecal occult blood testing. BMC Cancer 2015;15:705.

19 Huang W, Liu G, Zhang X, et al. Cost-Effectiveness of colorectal cancer screening protocols in urban Chinese populations. PLoS One 2014;9:e109150.

20 Winawer SJ, Zauber AG, Ho MN, et al. Prevention of colorectal cancer by colonoscopic polypectomy. The National Polyp study Workgroup. N Engl J Med 1993;329:1977-81.

21 Vleugels JLA, van Lanschot MCJ, Dekker E. Colorectal cancer screening by colonoscopy: putting it into perspective. Dig Endosc 2016;28:250-9.

22 Imperiale TF. Noninvasive screening tests for colorectal cancer. Dig Dis 2012;30 Suppl 2:16-26.

23 Murphy J, Halloran S, Gray A. Cost-Effectiveness of the faecal immunochemical test at a range of positivity thresholds compared with the guaiac faecal occult blood test in the NHS bowel cancer screening programme in England. BMJ Open 2017;7:e017186.

24 Goede SL, Rabeneck L, van Ballegooijen M, et al. Harms, benefits and costs of fecal immunochemical testing versus guaiac fecal occult blood testing for colorectal cancer screening. PLOS One 2017;12:e0172864.
25 Ladabaum U, Alvarez-Osorio L, Rösch T, et al. Cost-Effectiveness of colorectal cancer screening in Germany: current endoscopic and fecal testing strategies versus plasma methylated septin 9 DNA. Endosc Int Open 2014;2:E96-104.

26 Lansdorp-Vogelaar I, Knudsen AB, Brenner H. Cost-Effectiveness of colorectal cancer screening. Epidemiol Rev 2011;33:88-100.

27 Greuter MJE, Berkhof J, Fijneman RJA, et al. The potential of imaging techniques as a screening tool for colorectal cancer: a costeffectiveness analysis. Br J Radiol 2016;89:20150910.

28 Phisalprapa P, Supakankunti S, Chaiyakunapruk N. CostEffectiveness and budget impact analyses of colorectal cancer screenings in a low- and middle-income country: example from Thailand. J Med Econ 2019;22:1351-61.

29 Skally M, Hanly P, Sharp L. Cost effectiveness of fecal DNA screening for colorectal cancer: a systematic review and quality appraisal of the literature. Appl Health Econ Health Policy 2013;11:181-92.

30 Liang M, Li Y, Li K. Effect of medical insurance and enteric preferential policies on complications of colonoscopy in colorectal cancer screening. J Trop Med 2018;18:340-4.

31 Lee K-S, Park E-C. Cost effectiveness of colorectal cancer screening interventions with their effects on health disparity being considered. Cancer Res Treat 2016;48:1010-9.

32 Lara CL, Means KL, Morwood KD, et al. Colorectal cancer screening interventions in 2 health care systems serving disadvantaged populations: screening uptake and cost-effectiveness. Cancer 2018;124:4130-6.

33 ZF L, Huang HY, Shi JF. A systematic review of worldwide natural history models of colorectal cancer: classification, transition rate and a recommendation for developing Chinese population-specific model. Chin J Epidemiol 2017;38:253-60.

34 MD L. Prognostic factors in 837 cases of colorectal cancer. Hangzhou: Zhejiang university, 2012: 15

35 Liu HZ, Lin GZ. Death cause surveillance in Guangzhou (20142015). 1st ed. Guangzhou: Yangcheng Evening News Press, 2018: 23-6.

36 Wong CKH, Lam CLK, Poon JTC, et al. Clinical correlates of health preference and generic health-related quality of life in patients with colorectal neoplasms. PLoS One 2013;8:e58341.

37 Zhou Q, HL L, YT G. Economic burden of patients with colorectal cancer and precancerosis in Guangzhou and its influencing factors. China cancer 2020;29:7-13.

38 Health Commission of Guangdong Province. Medical service price in Guangdong Province. Available: http://www.gdwst.gov.cn/Pc/Index/ search.html

39 Li Q, Yu L, Xue F, et al. [Evaluation of optimized sequential screening program of colorectal cancer in current China]. Zhonghua Yu Fang $Y_{i}$ Xue Za Zhi 2014;48:995-1000.

40 Wong WM, Lam SK, Cheung KL, et al. Evaluation of an automated immunochemical fecal occult blood test for colorectal neoplasia detection in a Chinese population. Cancer 2003;97:2420-4.

41 ZJ Y. Cost-Effectiveness analysis of high-risk group of colorectal cancer screening. Guangzhou: Guangdong Medical College, 2006: 27. 